\title{
Architectural design approach for morphing smart cities in Mexico
}

\author{
Ana Cristina García-Luna Romero ${ }^{1 *}$ \\ ${ }^{1}$ Universidad de Monterrey, Monterrey, Mexico
}

\begin{abstract}
This academic work aims to provide an intricate definition of the terms at hand as well as explain the relationship between smart cities and the sustainable development that they present based on a comparative analysis of case studies and experiences in the Mexican context. The endeavour to achieve being an architectural proposal of an innovative solution adapted to current conditions that will be carried out by an academic team, thus incorporating sustainable criteria, universal accessibility and social inclusion. This research work reflects the theoretical aspect, providing an intricate academic reflection and giving background information also establishing the complexity that lies within Latin American metropolis emphasizing in Mexican cities, as to provide insight into the academic dynamics in order to educate professionals on the field from an updated perspective in which they'll be able to determine and analyse the implementation of smart cities from an architectural standpoint and the impact they would have on the quality of urban life in those Mexican cities.
\end{abstract}

\section{Introduction}

Given the need to tackle sustainability issues that are present in cities and knowing the reality that exists today, the concept of Smart City provides numerous changes and advances for them. The Internet, together with Big Data, is transforming the way we develop our lives in cities, and its activity is expected to continue increasing exponentially in the coming years.[3]

However, there are multiple definitions and perspectives that try to give an approximation about the concept of Smart City.

According to Torres Pastor in 2007 it was observed that an adequate strategy and plans in cities would have a direct impact on both the clarity of life of individuals and the environment in them. [19]

Therefore, a city like Tokyo, with approximately 35 million residents, has less pollution than Delhi, which is almost 16 million. Therefore, this clearly shows the importance of good management of city operations, so that the Japanese capital has $4 \%$ less pollution than the Indian capital. [14]

The concept of sustainable cities began to develop in the 1980s, trying to represent a response to the challenges facing cities. The sustainable development is understood as the development that can meet current needs without harming the needs of future generations [21]. It usually has three components: society, environment and economy, which are very close to the needs of cities.

Therefore, in 2011 it was proposed to formally include the concept of smart cities, turning sustainable cities into Smart Cities. Thus, it is proposed as a definition that "a smart city must invest in transport and infrastructure based on ICT, as well as in social and human capital to promote sustainable economic development and a higher quality of life and manage efficiently and effectively the natural resources available to it through participatory actions and the commitment of its citizens." [2]

In this way, when studying the growth of the world's population and the cities themselves, the importance of these cities (that is, smart cities) becomes the key. Both situations should arouse people's attention. Construction or engineering. The increase in urban population has led to organizational, social and territorial management problems and environmental degradation.

\footnotetext{
${ }^{*}$ Corresponding author: ana.garcialuna $@$ udem.edu
} 
Therefore, the goals of this new urban phenomenon are focused on transforming cities, establishing this transformation in sustainable development, and managing resources and activities at all levels with innovation as a key technological element.

In this way, it is possible to present the smart city model as a future city under an innovation-based ecosystem, which requires collaboration and cooperation between public and private entities.

In modern cities, specifically those belonging to developed countries, there are numerous projects that have emerged (at the hands of public and private entities) to exploit and carry out this new dynamic (see Fig. 1). This is an economic development focused on intelligence and sustainable and innovative technologies.

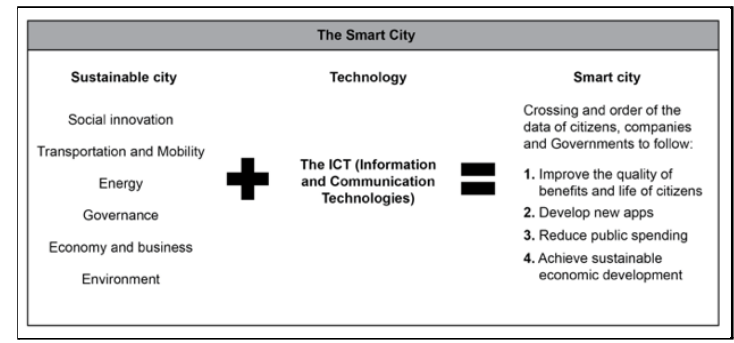

Fig. 1. The Smart City approach.

Therefore, despite being a novel concept, Smart Cities are of special interest both locally and internationally as it implies a transformation of conventional cities towards smart to innovative. In this way, it seeks to reflect on this issue in relation to Latin American countries, specifically for this research project in Mexico, to contribute to the development of sustainable cities from a transdisciplinary approach between architecture and technologies.

On the other hand, in terms of evaluating this type of city, it is not an easy task, because the ranking of the city positioning is different under this phenomenon. Among them are the following prominent: Juniper Research Institute or IESE. Specifically, the first of them updated the rankings at the end of 2017, listing Singapore, London, New York, San Francisco and Chicago as the world's five best smart cities. [8]

Based on all the above, the smart city concept has undergone great development since its birth. It started from the idea of focusing only on technology, and its main goal is to achieve effective services and technologies through integration. A human-centred global joint concept, therefore, it needs to include other variables related to quality of life, innovation or economic progress. [16]

The concept is summarized at the intersection of all its vertical elements (energy, governance or life, etc.) and horizontal elements (ICT) [7]. Therefore, technology is not a decisive measure in a smart city, because civic

education or company innovation and city planning, and management are all necessary prerequisites.[7]

For this research the concept of intelligent city of Giffinger, who defined this new concept of the city as the place where a clever combination between resources and actions of citizens occurs is taken, who are characterized by independent, responsible individuals and with some decision-making ability. [6]

This definition meant a turning point, because it was from this definition that the human figure was taken into account as the main purpose of urban development. After that, when the draft city spread on the international stage, many ICT and cities were born as Service companies. [10]

Therefore, this phenomenon will depend both on the different fundamental infrastructures of the city (physical capital) and on the quality of information and the social infrastructure (social and intellectual capital) existing in the city. [1]

Thus, each city uses and defines its own smart city model, so that it is consistent and in line with its main characteristics. According to the definition given by Giffinger (basis for this research), Smart Cities present a series of concrete pillars or axes: "smart economy, smart people, smart government, smart mobility, smart environment and smart life." [6] The author, therefore, framed the concept under six characteristics defined from a series of factors and indicators in fig. 2. 


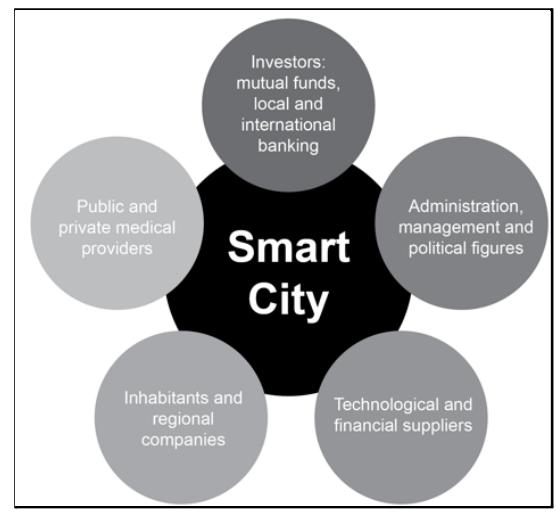

Fig. 2. Key agents of the smart city.

Under this term and from the case of Cohen and his Smart City wheel, it is observed in fig. 3 the way in which all the terms of said wheel relate to the future of sustainable development in the city.

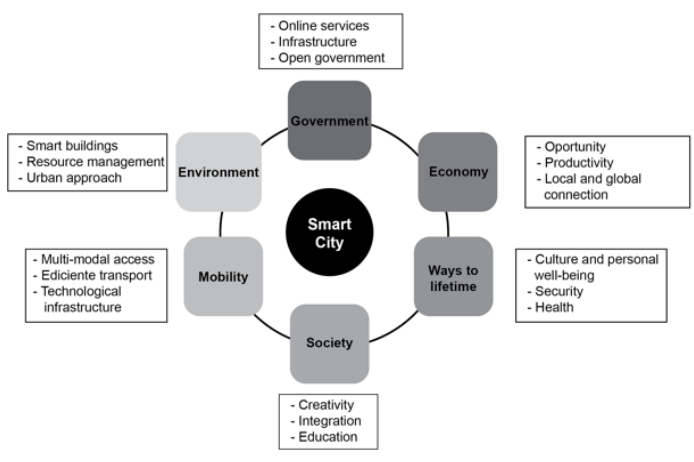

Fig. 3. The Smart City Wheel.

\subsection{New paradigms for LATAM}

The term "smart city" promotes that cities will drive a higher quality of life of citizens, and improve economic conditions since people across the world will live in urban environments within the next few decades.

Steve Jobs, said: "as you evolve that great idea, it changes and grows. It never comes out like it starts because you learn a lot more as you get into it. And you also find there are tremendous trade-offs that you have to make." [5]

The imperative forces driving smarter cities (including economic health, poverty reduction, improved healthcare, better use of our natural resources, reduction of crime and management of the planet) are very real, and technology empowers leaders to transform A vibrant and healthy city with their capabilities is also promising.

Technology has improved roads, transportation systems, and modern infrastructure through improved analysis capabilities, thereby increasing resilience; it can also improve our education and medical systems and make our cities safer and more streamlined.

However, these changes don't and won't happen just because we connect people and buildings to sensors and digital services. Data collection through ICT is simply and enabler of smarter cities.

Ultimately, only by guiding policy and technological innovation within a unified framework can we ensure positive changes and ensure that humans can lead a healthy and productive life without affecting our natural resources.

According to the United Nations, by $2050,66 \%$ of the world's population is poised to live in urban environments. Similarly, the World Bank estimates a doubling of urban population by 2030, tripling the global urban land area from just 2000. [20] 
However, we can easily reach a consensus: the urban environment will continue to affect the majority of the world's population, family, friends, neighbours, and our daily lives in terms of basic health and safety and those that make life meaningful to each of us jobs.

And the configuration and management of our cities will persist in playing a direct role in our safety, economies, and depth of community relationships. The better we plan, build, operate, and maintain our cities, the more competitive, resilient, healthy, and sustainable our urban communities will be.

\subsection{Smart Cities expectative}

The city is not just a place to live. They are diverse and usually have important historical depth, beauty and work, as well as deep community, religious and ethnic significance. Indeed, urban planners and architects can benefit greatly from the systems and tools developed by technicians in these well-funded ecological projects.

Rapid urbanization has brought enormous challenges, including the transfer of poverty from rural communities to cities, and a higher demand for basic services, jobs, and affordable housing, especially in Mexican cities and many other Latin American countries.

Smart technologies will undoubtedly play a role in this transition, and it depends on our city leaders adapting to these technologies in a meaningful and principled way. Technology can help cities become more liveable in many ways. It can help introduce a sense of security, well-functioning infrastructure, economic health, affordability, green space, and natural and cultural assets. What it cannot do is to replace the important relationship between people, their communities and the environment they build. [18] The pursuit of ideal cities is not new. Building cities on a human scale should be a priority.

What's needed now is an approach to building smarter cities that not only incorporates the issues of buildings technologically advanced smart cities but also comprehends the shifts in human living within these environments.

As more data is considered, design opportunities become bigger and bigger. As analytical techniques improve and people understand how to better access data, use the data correctly and improve its interpretation capabilities, designers will become more capable.

According to presented information we can set that: first, technology-centric planning is not a neutral exercise which means that smart cities are challenged when technology-centric planning is pursued without regard for broader implications in the safety, regulatory, and social spheres. Therefore, technology should be considered as part of an overall.

Therefore, various architectural-urban design methodologies encourage city planners to shift their thinking from outcomes to process by framing smart city issues in the context of goals rather than discrete problems.

By definition, smart cities aim to improve the functioning infrastructure, access to resources, and safety and security for the population.

Second, thinking Glocal increases our sense of responsibility since Glocal describes the adaptation of broad solutions to local needs and desires. With advanced technologies and especially social media, what is local is quickly shifting as we learn about the lives and struggles of others across the world and move to influence them.

Because of this new level of global consistency, cities around the world have begun to adopt a joint structure. The behavior of local citizens is quite collective, and where and how technology will be used in the ever-growing urban Internet work will be profoundly affected.

Third, safety, social factors, and regulation all influence technology planning since safety, social factors and policy considerations are all key in technology planning. Although today's technology is highly specialized, fragmented uses will diminish as our cities grow evermore connected and new uses for data emerge.

Although, changes in data requirements and the ability to analyze data and provide corresponding services to cities and citizens mean that each sensor may help achieve unexpected goals. 
Moreover, infrastructure operations such as energy, water, transportation and public safety are being integrated into consumer-centric services, which will improve people's lives, not just provide goods. City planning must reflect this important change.

Fourth, resource issues can best be treated with integrated solutions since designs for smart cities must include treatment for energy efficiency, energy intensity, and energy emissions intensity. Resource issues must be well defined and understood if they are to be optimally managed.

Home smart devices will continue to be favored by consumers, but other industries (especially commercial buildings with networked sensors, centralized monitoring and unified control) will save a lot of costs and resources, mainly energy.

As last, fifth, the building sector provides significant opportunity since the current building sector accounts for nearly half the consumption across the world. Buildings management technology can provide meaningful gains, but it requires a strong understanding of behaviour.

In this manner, heating, cooling, and lighting comprise a significant opportunity to automate office spaces, retail operations, and educational institutions, but solely relying on automation for positive change may not work well if the behaviour of the occupants is not understood.

Also, building management systems can put the Internet of Things (IoT) to good use to mitigate poor configurations, and help account for behaviour issues that can trouble even well-engineered buildings.

Therefore, human-centric design for addressing building management challenges by accounting for human habits, behaviours, schedules, and preferences helps build trust and confidence among occupants to positively influence their behaviours within the building.

This research work seeks to highlight the importance of understanding the more subjective components of place and what happens in certain spaces in order to incorporate that knowledge into the creation, measurement, and validation phases of smart city design for Mexican cities.

When designing for the urban environment, planners should prioritize the people for whom they are designing for in order to participate in an act of co-creation. Antoine de Saint-Exupéry said, "if you want to build a ship, don't drum up people to collect wood and don't assign them tasks and work, but rather teach them to long for the endless immensity of the sea." [4]

Obviously, the French writer didn't mean that building a good ship isn't an important step in taking on a venture of ocean exploration. But he reminds us that no matter how awesome in magnitude and prowess our flotilla may be, if we have no reason for building it and we can't convince others that we have a reason, then in the end we have wasted our time. Instead, we begin with understanding. [18]

Unfortunately, designers and technology-oriented solution providers rarely cooperate. Cities have complexities and challenges that can be solved with disruptive technologies, but in order to establish sustainable, purposeful solutions, non-technical strategies must also be considered.

As much as technologists need to think about the people that their applications both serve and impact, designers must gain inspiration and validation from data driven information. Designers who are working within the context of a digital world should maintain basic knowledge, beyond the intuitive, as to how to value the communication network. Designers should be able to envision how network connections actually work, how a specific design might be implemented or scaled, and how these designs might impact strategic plans to provide value to urban dwellers.

It is not always that simple, because multiple values may be created in the network, and new devices and new methods of using these devices will continue to create values for cities and citizens that have not yet been thought of or cannot be determined.

\subsection{Sociospatial perspective: people in space, before place}

This research work attempts to challenge how we view cities as smart city models from the design of Mexican cities and related design processes, advocates for a more humane perspective, and uses understanding design processes to help guide innovation to move nodes. That point (Including hardware and human types), then we must seek the quantitative value derived from the use of network analysis to help us speed up work, measure the impact of design, and 
respond quickly and rework when necessary. Two forms of analysis are immediately useful, including social and spatial analysis. Although both spatial and social network analysis techniques are tools that use various graph-based analyses to illuminate our virtual and physical environments, they are rarely used together.

Social space generates change in our urban environment, but it is more than a producer; it's also a product of the interactions between our built environment and our social actions. And most critically, social processes are no longer influenced by just our behaviours in space; they're also affected by our behaviours in place.

Most importantly, our urban world is now virtual and physical, and our analysis of social and spatial network behaviour can help us design and measure the effectiveness of plans related to urban space life. The way we use urban space directly affects our social relationships. Spatial and social network analysis tools cannot be well integrated to understand the people in the space inhabited at the time (especially in the context of digital relationships), so people can draw meaningful conclusions about how the integrated world will develop.

On the other hand, advancing people's social relations research through human geography may be the key to comprehensively achieving a deep and useful understanding of people in digital communication networks (especially in smart cities). These studies have found that specific communities and cultures set boundaries around their relationships in space and place.

Human geographers study animals, economy, population, politics, and of course rural and urban settlements. This is not a new field of research, but digital social networks are developing very rapidly, and their power is creating new environments that have not been well resolved, especially the collapse of virtual interactions in our physical spaces and places.

There is a difference between space and place, and it will increasingly become more than an academic concern for urban designers working with people in the context of the Internet of Things. April McCabe [12] says, "space is one-dimensional and is only a physical location, Place, however is multi-layered and subjective. It is created when the physical attributes, emotional connections, and psychological perceptions are combined to impart individual meaning and value."

Therefore, it should be understood that a single space can be a setting of multiple places, which is almost the same way that a gallery can be used for a book club, art performance or cocktail party. Regarding reflection: are we designing for spaces, places, or both?

\subsection{Intelligent skins: architectural approach}

This paper promotes that throughout the design process a novel material system should be used for allowing sensing, form-changing and luminous capacities for responsive and kinetic architecture through an experimental design in the form of an architectural skin. Through experimentation with alternative materials and a rigorous process for a responsive design system for Mexican cities have emerged from this research.

Therefore, the design investigation explored the potential of using deformable materials with capacitive sensing, energy absorption and lighting functions for deforming architectural skin that can respond to proximity and lighting stimulation.

In responsive kinetic architecture, the idea of responsive building skins is often explored through designing individual sensing components that have discrete mechanisms and movements. This architectural approach is not new and has been explored since the 1960s, for instance, the responsive brise-soleil of the Los Angeles County Hall of Records, designed by Richard Neutra in 1962, is one of the first significant examples of responsive architectural skins. [17]

These structures and systems hindered the mainstream adoption of responsive building skins because of their expensive sensing system and brittle mechanical components.

The search for alternatives led this research to explore ways to design a responsive building appearance using fewer machinery and sensing devices. Advances in materials engineering technology provide opportunities to use passive and active deformation technologies such as shape memory alloys (SMA), elastic silicone polymers, and phosphorescent luminescent pigments to design dynamic and responsive architectural appearances. These soft and deformable materials can be integrated with other sensing materials. The deformed building skin provides an alternative method to solve the brittleness problem in the operation of machinery and sensing systems. 
According to Leslie Momoda, the multifunctional material system would require a combination of three or more functions, including logic, sensing, energy storage, structure and actuation. [15]

The research presented in this paper aims to explore form and materials that can perform illumination, and function as both an actuator and sensor in responsive architectural designs. This research investigates whether this kind of material exists. In addition, if it does, how to apply this in a responsive architectural design context.

These initial inquiries motivate this investigation into unexplored approaches using responsive and form-changing materials. It extends opportunities for designing responsive morphing architecture with hinge-less actuation and transformation.

By using emerging form-changing materials and alternative tools, a responsive morphing architecture can be achieved with fewer mechanical components and devices. This approach formed an investigation into the potential of existing form-changing materials to design responsive architectural design in the form of morphing skins.

This investigation eventually generated the concept of "responsive materiality". Responsive materiality offers an initial concept of movement and change in response to material properties rather than changes in mechanical components, such as actuated motors and gears, in the responsive kinetic architectural context. Current material advancements have allowed this concept to become a reality in which materials with sensing, actuating and feedback loop capacities respond to external stimuli. [11] Contemporary architects and designers can now reconsider the traditional relationship between architecture and material practice. [9]

\subsection{Responsive materiality in architectural designs}

There are several precedents related to the concept of responsive materiality in architectural designs. For instance, a materially actuated responsive skin without any kind of mechanics, electronic control or supply of external energy. It creates a new range of possibilities that propose that materials can actuate as well as sense. This purely passive approach suggests that zero-energy responsive architecture is possible. [13]

However, once the material is programmed during the fabrication process, the responsive behaviour of the material properties is fixed and unchangeable. Instead of being a negative issue, this passive approach provides an opportunity to further explore a possible hybrid approach that includes passive and active responsive abilities within the materials' properties that can control various states after they are manufactured.

Whether there is a system that exploits both passive and active approaches. There is an opportunity to create a hybrid system that involves passive and active implementation to fully exploit the advantages of both approaches.

By using responsive materials, this different approach implies a great potential for material systems to perform transformations and other adaptive capabilities within material properties. This design inspiration establishes the first step for design investigation to further explore the full potential of this responsive and different response design concept.

On the other hand, when designing for the urban environment, planners must consider the human and social scale of the people they are designing before they can participate in creative activities. This article first points out the following points in order to design the urban environment of human smart cities abroad.

Firs, designing for inspiration; cities have complexities and challenges that can be treated with disruptive technologies, but non-technological strategies must also be considered in order to build sustainable, purposeful solutions. By reframing urban challenges in a way that improves that value of what we learn from analytics, design methodologies practices can dramatically improve the way that data drives new insights. Equally, analytics validate the value of human-centric innovation.

Second, understanding networks helps us understand evolving patterns and connections in the city. The ability to analyse both individual choices and those in aggregate is key to the efficient use of our resources; it's also critical to understanding how the choices of people change as their social group evolves.

Third, we all are people in space and place; and designers must understand how network connections actually work, how a specific design might be implemented or scaled, and how these designs might impact the city will create as-of-yet unconceived or unidentified forms of value. 
Therefore, this article advocates the teaching focus of network evaluation. Urban planners and product designers can consider a variety of methods to consider the power of connection in design. Therefore, the best fit should be evaluated based on the project background and the appropriate use of any of these models to help unlock the design potential.

Fourth, rising for the benefit of the people; our lack of desire to tackle human problems should not be justified. We need to reframe this perspective to move forward since we tend toward black and white thinking, where smart cities are going to be all good or all bad, depending on who you ask.

However, we lacked dialogue on the important issues raised and the willingness to establish a framework that would help alleviate some of the concerns that have intensified us.

Smart cities must focus on the goal of creating a place where it is easier to make decisions, proactively solve potential problems, and carefully allocate our resources. This article takes Monterrey, Mexico as a research case, and focuses on the design process, thereby promoting the reflection of smart cities.

\section{Architectural exploration for the implementation of the smart city}

The purpose of Ho's academic work is to determine the concept of a sustainable smart city based on a comparative analysis of Mexican case studies and experience.

In these results, in addition to confirming that technology has penetrated into all human activities, it is a smart and sustainable city, and modified it to the extent that it can change the urban environment and urban structure. This is because information accumulates in it and generates know-how.

\subsection{Background}

First, the world population has grown from 2.5 billion people in 1950 to more than 7,000 in 2015 . The forecast according to UN estimates is that the population will increase to 9.7 billion in 2050. A large part of this population $(60 \%)$ lives in cities. By 2050, $75 \%$ are expected to do so. In Europe, $80 \%$ already do so and in Latin America and the Caribbean $75 \%$.

Secondly, cities have grown in a disorderly manner creating major urban, social and environmental pathologies. According to the UN, in 1990 there were 10 megacities (cities with more than 10 million inhabitants), in 2014 this figure increased to 28 and it is estimated that in 2030 there will be 41 . Some of these cities have difficult remedies (Delhi, Mexico City, São Paulo). In many of them the benefits of agglomeration economies do not outweigh their costs.

Third, we may be in time to act on medium-sized cities with a population of between 100,000 and 2 million - to make them more humane. They are the cities that are showing the highest growth in population and wealth but run serious risks of not being able to control this growth, which leads to an increase in pollution, informal human settlements, inequality and poverty.

Finally, there is a consensus in understanding cities as a "complex holistic system", which does not mean anything other than the problems of cities - which affect many sectors - must be approached from an interdisciplinary perspective (urban, economic, social, and environmental).

\subsection{Cases in Latin America}

Latin America is a developing region with the highest urbanization rate on the planet. The trend estimated by the United Nations indicates that by $2050,90 \%$ of its population will live in cities. This is a huge challenge for those countries that have not yet managed to solve the huge challenges of these huge urban agglomerations, namely poverty, insecurity, pollution and mobility.

Take Mexico as an example. When designing a smart city, a strategy must be formulated, which includes the mission, vision, and goals to be achieved. In this case, it makes sense to innovate and incorporate ICT to obtain information and provide effective responses.

The smart city is classified into six categories: smart government, smart environment, smart economy, smart mobility, smart citizens and smart way of life. Latin America presents room for improvement in all of them and also has models in which other regions of the planet must look. 
This is because we are convinced that the deployment of smart cities is not only about the deployment of electronic sensor devices, but also involves high costs, although they may help to obtain some effective, objective and real-time information of interest.

What really defines a city as a smart city is its ability to meet the needs of the population and provide appropriate and effective solutions to satisfy them.

Therefore, it is impossible to confuse the goal of building a smart city with the goal of combining novel solutions that can be easily implemented by ICT.

In summary, considering that there is no innovation without tradition, it seems that when faced with a large number of proposals to invade new technologies, the purpose is to improve the competitiveness of cities in terms of efficiency.

To clarify the innovation of the mechanism to enable people to respond to the needs of the people, comply with their expectations, and be able to provide public services more effectively. It is the people who are essentially living with these people. No matter what smart project is implemented, they must constitute a mandatory reference and play a leading role in the decision adopted.

The construction of smart cities is only understood in the context of a democratic and participatory society, so that the empowerment of the population constitutes its own and not attributed right. This entails the need to implement a governance model, through intelligent platforms and projects, that houses and enables communication and interaction between citizens, public institutions, companies and any other social organizations. Governance and co-government, in an open data scenario, is only possible in democratic societies.

\subsection{All of this leads to the Integral Project I and II semester Fall 2020}

UDEM's integral design course 1 of 4 th year of the architecture degree for the development of the integral project I and II aims to prepare an architectural proposal that proposes an innovative solution adapted to present conditions and future generations for a basic education campus (pre-school, elementary and junior high) located in the AMM.

For the theme of the overall workshop of this semester, we will study some of the locations of AMM elementary and junior high schools built in the 20th century. These locations currently have very special significance. Some of these schools are located on large tracts of land (from one hectare to several hectares), they are located in a consolidated urban environment, close to communication lines, public transportation, and are usually on flat or very low slopes.

These characteristics make them (unfortunately) very attractive for real estate speculation, as these are ideal properties to become high-density commercial or residential use, and candidates for obtaining a "high capital gain" with the transformation of land use.

On the other hand, the recent suspension of classes due to COVID19 has forced us to consider how to reconsider how school activities are conducted, especially pre-school, elementary and junior high-level activities.

Some questions that arise are, is it necessary to go to school every day? How has education, learning and training done and will telework differently? Better or worse?

Can the education of children and the work of the student's father/mother conjugate in the same school? Just as the city must be densified, should we seek to densify schools in a way of "mixed uses" related to their activity? current sports use (courts) in schools? Or can we perhaps consider others that are more attractive to the boys and girls of the 21st century?

Based on these and other approaches and the workshop's deliverable schedule, an integral Project (conceptual proposal + preliminary project + executive project) will be carried out during the semester that incorporates sustainable criteria, universal accessibility, and social inclusion.

Located in a new or existing property (reconversion) for a Basic Education school, for which it is necessary to:

1. The nine students will be divided into four teams.

2. The students identify a suitable property for their project located within the urban area of the Monterrey Metropolitan Area.

3. The professor will authorize each team the property and location of the project according to the parameters established in their group. 
4. They begin the exploratory and conceptual work for their project and with the investigation of the Montessori educational system, taking into account the aforementioned aspects of sustainability, accessibility and inclusion, and especially the post-COVID19 conditions that are expected in the near future.

\subsection{Some rules for the project}

- It can be done in teams or individually

- Parking spaces will be underground as much as possible or will be eliminated, favouring the use of public or local transport.

- Find land / sites of at least 5,000 m2

- The trend in the regulations is towards a free CUS, but it is recommended:

o COS: 0.75 maximum

o CAS: 0.25 (free area) minimum

o CUS: 3.0, which throws at least one of the buildings on multiple levels.

- Review the files "Turns for public SPGG equipment" and "Giros for private SPGG equipment" as a reference for the elaboration of the program.

\subsection{Project exhibition and presentation}

This semester will install the digital works exhibition of the "Integral Architecture" seminar to replace our exhibition at CRGS. During the semester, they will be asked to prepare a project introduction form in the format of "Final EACH Poster Template", which is the format used by our School of Architecture and Human Settlements.

\subsection{Design process phases}

First, the preparation phase begins and lasts for three weeks, starting on January 13 and ending on February 2. In the first week, you will see site and project introductions, analyses and diagrams as well as presentations and presentations. Visit the site (will be organized by each group and teacher).

In the second and third weeks, work on conceptualization, volumetric diagrams and conceptual representation will be carried out.

This stage focuses on schematic design and will provide the following contents: site analysis, detailed building procedures, conceptual drawings and the relationship between spaces, function analysis, volume definition, and reflection of project and urban proposals.

Then follows the preliminary project phase, which lasts four weeks and is worth $20 \%$; begins on February 3 and ends on March 1.

In the first week the structural concepts and feasibility will be seen first; after this we will see the types of structures and the parametric costs.

The second week will see the presentation of structures and costs, the conceptual draft, and the review of plants and percentages of areas.

In the third week the sudden results and the architectural project will be seen.

Finally, in the fourth week the elevations and cuts will be reviewed; as well as the revision of the architectural blueprint and the section of the building.

This phase focuses on design development, performing the following: definition of floors and volumes, architectural plans with their indications, cuts (minimum 2 and facade study), facades, structural solution, render(s), and overall plan.

The third stage will focus on the exhibition model, drawings and exhibition model of CRGS. The model will last two weeks and is worthwhile with the fourth stage (20\%).

This phase starts on March 2 and ends on March 15. During this period, we will focus on speeches, video conferences or visits, and will deliver the work as follows: 3D structure model, presentation slides, exhibition design and your project. 
The fourth phase focuses on the preparation of individual sheets and models, lasting only one week, starting in March 16 to March 22.

The work to be delivered during this phase will go together with the next phase: the executive project, which will last seven weeks, starting on March 23 and ending on May 10.

The deliverables for this phase are the following: cover, plants, constructions cuts and by façade (as necessary), structural scheme in isometry or model, structural walls/columns (general scheme), structural beams/slabs (general scheme), wall offset, floor finishes (includes soffits and roofs), exploded floors, façade finishes, blacksmithing and carpentry, crystals (includes windows), and hydraulic and sanitary plans.

During this week, the exposition will take place; on March 23 we have the assembly of the Expo Structural Model; then on March 24 is the inauguration of the Model Expo. The exposition ends on April 3, on this day you will disassemble your projects.

After this we have Holy Week and after that we will focus on your executive projects.

The next phase goes along with the one before, focusing on the Executive project. This phase along with the one before are worth together $40 \%$.

The fifth stage starts on April 20 and ends on the last day of school on May 8. The building plan to be delivered is as follows: lightning and electrical installation accessories, electrical installation, light rain, air conditioning, landscaping and outdoor areas, special projects (including safety, automation, home automation), descriptive memory and catalog of materials, equipment and accessories.

Finally, in the final stage (May 11 to May 24, a two-week final exam), you will submit the final exam according to the date in the official calendar.

\section{Conclusion}

It's dangerous to be inaccurate in our statements about the smart city, given the tremendous need to improve our urban environment.

Therefore, smart cities are a relevant topic. Thus, to build smarter cities that not only incorporates the issues of building technologically advanced smart cities, but also comprehends the shifts in human living within these environments.

We need a plan for smart cities that leverages our best learning about technology but that fully acknowledges the importance of creating and sustaining vital communities.

In our cities, where our buildings stand tall; our streets roll long; and our movements create an urban buzz composed of busker music from the subways, slamming car doors, engine brakes.

In short, it is the buildings where we live, live, work, and are often born and die. Their personal property will support our maximum ability as human beings or demolish them.

All these factors, coupled with global transportation, infrastructure and climate constraints, drive extremely complex conditions, and we are dumping a lot of money and resources here to build smart cities.

However, the reality in Latin America is more complicated, but this does not mean that there is no need for smart cities. This research work reflects academic dynamics, educating architectural professionals from a comprehensive and up-to-date perspective to improve the quality of life in Mexico City.

\section{Acknowledgments}

Many thanks to Prof. Dr. Debopriyo Roy from the University of Aizu, Japan for giving me the opportunity to participate in the conference. Above, for his effort promoting international and interdisciplinary research projects. 


\section{References}

1. Berry, C., \& Glaeser, E. (2005). The divergence of human capital levels across cities. Papers in Regional Science.

2. Caragliu, A., Bo, C. D., \& Nijkamp, P. (18 de Febrero de 2011). Smart Cities in Europe. Journal of Urban Technology, pgs. 65-82.

3. Cárdenas, J. L. (3 de Noviembre de 2020). El Big Data y el Internet de las Cosas pueden cambiar comportamientos. Europa Press.

4. De Saint-Exupéry, A. (n.d). Brainy Quote. Retrieved May 14, 2015, at http://www.brainyquote.com/quotes/quotes/a/MIBmTKrc0vawLPfH.99

5. Elmer-DeWitt, Phillip. (2011) Steve Jobs: The parable of the stones" Fortune. Retrieved November 20, 2020, from $h t t p: / / f o r t u n e . c o m / 2011 / 11 / 11 /$ steve-jobs-the-parable-of-the-stones.

6. Giffinger, R., Fertner, C., H. Kramar, N. P., \& Meijers, E. (2007). Smart Cities Raking of Europeas Medium-Sized Cities. Viena: Centre of Regional Science. Universidad Tecnológica de Viena.

7. ICEX. (27 de Julio de 2015). "Smart cities", la tecnología es clave. Madrid, Madrid, España.

8. Juniper Research. (2017). Smart Cities: Strategies \& Forecasts in Energy, Transport \& Lighting. 2017-2022. Hampshire : Juniper Research Ltd.

9. Kennedy, Sheila. 2011. "Responsive materials." In Material design: Informing architecture by materiality, edited by Thomas Schropfer, 118- 131. Basel: Birkhauser GmbH.

10. Kogan, N., \& Jung, K. (2014). Exploratory research on success factors and challenges of Smart City Projects. Kyung Hee: Kyung Hee University .

11. Kolarevic, Branko. 2004. "Designing and manufacturing material in the digital age." In Fabrication: Education summit white papers, edited by Aron Temkin, 52-55. Toronto: University of Waterloo School of Architecture Press.

12. McCabe, A. (n.d) Space vs Place: Defining the difference. Retrieved November 6, 2020 from http://www.placepartners.com.au/blog/space-vs-place-defining-difference.

13. Menges, Achim, and Steffen Reichert. 2012. "Material capacity: Embedded responsiveness." In Material computation: Higher integration in morphogenetic design, vol. 82, AD, edited by Achim Menges, 52-59. West Sussex: Wiley-Academy.

14. Miller, D., \& Hanzel, G. (2007). Megacity challenges: a stakeholder perspective. New York : Siemens AG.

15. Momoda, Leslie A. 2005. "The future of engineering materials: Multifunction for performance: Tailored structure." Proceedings of the tenth annual symposium on Frontiers of Engineering, 10 (2005): 47-52. Washington D.C.: National Academies Press.

16. Quezada, T. M. (2015). Smart cities para el desarrollo económico y social a través de las TIC. Santander, España: Universidad de Cantabria.

17. Sample, Hilary. 2012. A brise-soleil without a building. In Matter: Material processes in architectural production, edited by Gail Peter Borden and Michael Meredith, 329-339. Oxon: Routledge.

18. Stimmel, C. (2016) Building smart cities. Analytics, ICT, and Design Thinking. Taylor \& Francis,

19. Torres Pastor, A.. (2018). Las smart cities y su implementación. Los casos de España y Dinamarca. Octubre 2020, de Universidad Pontificia Comillas Madrid Sitio web: https://repositorio.comillas.edu/xmlui/handle/11531/23754

20. United Nations (2014) World Urbanization Prospects: 2014 Revision. Retrieved November 20, 2020, from http://esa.un.org/unpd/wup/Highlights/WUP2014-Highlights.pdf

21. WCED. (1987). Our Common Future. World Commission on Environment and Development. Oxford, UK: Oxford University Press. 